\title{
O PROCESSO DE FORMAÇÃO DE PROFESSORES NO CURSO DE MATEMÁTICA DA FACULDADE DE FILOSOFIA, CIÊNCIAS E LETRAS DE MONTES CLAROS - MG (1968-1978)
}

\author{
DOI: http://dx.doi.org/10.1590/2236-3459/65905
}

\author{
Shirley Patrícia Nogueira de Castro e Almeida \\ Universidade Estadual de Montes Claros (Unimontes), Brasil \\ Maria Laura Magalhães Gomes \\ Universidade Federal de Minas Gerais (UFMG), Brasil
}

$\cos 80$

\begin{abstract}
Resumo
Este artigo relata os resultados de uma investigação sobre o período inicial (1968-1978) do curso de Matemática da Fafil - Faculdade de Filosofia, Ciências e Letras de Montes Claros, Minas Gerais. Além de documentos escritos, foram usadas 16 entrevistas, com base na metodologia da História Oral. $\mathrm{O}$ estudo mostra que, como em outras instituições brasileiras, a implantação do curso foi feita em caráter de urgência, num cenário de carência de professores do ensino secundário e superior. Mesmo tendo formado poucos licenciados em sua fase inicial, o curso pôde suprir algumas demandas. O modelo de formação adotado, calcado no rigor e na distinção, mostra a predominância da ideia de que as tarefas de ensinar e aprender Matemática eram destinadas aos bem dotados intelectualmente.

Palavras-chave: formação de professores de Matemática, história oral, história do curso de Licenciatura em Matemática da Universidade Estadual de Montes Claros (Unimontes).
\end{abstract}

\section{THE PROCESS OF MATHEMATICS' TEACHER EDUCATION IN FACULDADE DE FILOSOFIA, CIÊNCIAS E LETRAS DE MONTES CLAROS - MG (1968-1978)}

\begin{abstract}
This article reports the results of an investigation about the initial period (1968-1978) of an undergraduate course offered by Fafil - Faculdade de Filosofia, Ciências e Letras in Montes Claros, state of Minas Gerais, designed to prepare Mathematics teachers. In addition to written documents, the sources used were 16 interviews, based on the methodology of Oral History. The study shows that, as in other Brazilian institutions, the implementation of the course was made on an emergency basis, to provide teachers for the region of Montes Claros. Even with a small number of graduates in its early stages, the course was able to meet some demands. The adopted training model, based on rigor and distinction, shows the predominance of the idea that the tasks of teaching and learning mathematics were aimed at gifted intellectually students.

Keywords: Mathematics teacher's education, oral history, history of the Mathematics course in the State University of Montes Claros (Unimontes).
\end{abstract}




\section{EL PROCESO DE FORMACIÓN DE DOCENTES EN EL CURSO DE MATEMÁTICA DE LA FACULDAD DE FILOSOFIA, CIÊNCIAS E LETRAS DE MONTES CLAROS - MG (1968-1978)}

\section{Resumen}

El presente artículo informa los resultados de una investigación sobre el período inicial (1968-1978) del curso de Matemática de la Fafil - Faculdade de Filosofia, Ciências e Letras de Montes Claros, Minas Gerais, Brasil. Además de documentos escritos, se utilizaron 16 entrevistas, basadas en la metodología de la Historia Oral. La investigación demuestra que, como en otras instituciones brasileñas, la implantación del curso se hizo en condiciones de urgencia, en un escenario de carencia de docentes de enseñanza secundaria y superior. Aún habiendo egresado pocos docentes en su fase inicial, el curso pudo suprir algunas demandas. El modelo de formación adoptado, basado en el rigor e en la distinción, revela la predominancia de la idea de que las tareas de enseñar y aprender Matemática eran destinadas a los intelectualmente favorecidos.

Palabras clave: formación de docentes de Matemática, historia oral, historia del curso de Docencia en Matemática de la Universidad Estadual de Montes Claros (Unimontes).

\section{LE PROCESSUS DE FORMATION DES ENSEIGNANTS DES MATHÉMATIQUES DANS FACULDADE DE FILOSOFIA, CIÊNCIAS E LETRAS DE MONTES CLAROS - MG (1968-1978)}

\section{Résumé}

Cet article rapporte les résultats d'une enquête au sujet de la période initiale (1968-1978) d'un cours de premier cycle offert par Fafil - Faculdade de Filosofia, Ciências e Letras à Montes Claros, État de Minas Gerais, conçu pour préparer les enseignants de mathématiques. En plus des documents écrits, les sources utilisées étaient 16 interviews, basée sur la méthodologie de l'histoire orale. L'étude montre que, comme dans d'autres institutions brésiliennes, la mise en œuvre du cours a été effectuée sur une base d'urgence, de fournir des enseignants pour la région de Montes Claros. Même avec un petit nombre de diplômés dans ses premiers stades, le cours a été en mesure de répondre à certaines exigences. Le modèle de formation adopté, sur la base de la rigueur et de distinction, montre la prédominance de l'idée que les tâches d'enseignement et de l'apprentissage des mathématiques ont été destinés aux étudiants intellectuellement doués.

Mots-clés: formation de professeurs de mathématiques, l'histoire orale, histoire du cours de Mathématiques à I'Université d'Etat de Montes Claros (Unimontes). 


\section{Introdução}

$\mathrm{N}$

a década de 1960, a região norte do estado de Minas Gerais começava a passar por um processo de modernização; ao mesmo tempo, nessa região tinha início a implantação do Ensino Superior. Segundo Rota Júnior e Ide (2016), uma instituição fundamental no principal centro urbano norte-mineiro, Montes Claros, nesse momento, foi a Faculdade de Filosofia, Ciências e Letras (Fafil), ligada à Fundação Universitária Norte-Mineira (FUNM). Esses pesquisadores entendem que 0 protagonismo da instituição se deve, em grande parte, à necessidade de formação de professores de modo que se pudesse ampliar o sistema público de ensino na região e reduzir seus elevados índices de analfabetismo, e enfatizam que a introdução dos cursos superiores no norte de Minas foi tardia em relação ao restante do estado. É oportuno destacar a transformação, ocorrida em 1989, dessa instituição privada na Universidade Estadual de Montes Claros (Unimontes) ${ }^{1}$.

De fato, dados do IBGE de 1959, relativos ao censo demográfico de 1950, mostram que Montes Claros, em suas zonas urbana e rural, tinha um índice geral de analfabetismo de 74,63\% e em 1956 contava com apenas cinco estabelecimentos de ensino secundário entre suas 78 unidades escolares. (ROTA JúNIOR; IDE, 2016).

Paula (1973) argumenta que, no início dos anos 1960, no sertão norte mineiro, em parte situado no Polígono das Secas ${ }^{2}$, que corresponde a um quinto do território do estado de Minas -, havia um total de cinquenta e sete instituições escolares de nível médio - 91\% de iniciativa particular e $9 \%$ públicas - para atender a quase um milhão de habitantes dessa porção regional ${ }^{3}$.

Com o objetivo de instituir e manter a Universidade Norte de Minas, a FUNM foi criada em 1962, pela Lei Estadual 2615, de 24 de maio, e tinha inicialmente a intenção de implantar uma Escola de Agronomia e Veterinária e um Instituto Superior de Pesquisa da Região (DRUMOND, 1989). Contudo, essa proposta não se concretizou. De acordo com Rota Júnior e Ide (2016), os primeiros cursos da instituição foram os de Pedagogia, Letras, História e Geografia, iniciados em 1962, "pela maior disponibilidade imediata do corpo docente e em virtude da necessidade da expansão do ensino secundário, que, como visto, era extremamente escasso na região, impossibilitando o próprio acesso ao ensino superior" (p. 153). Em 1968, passaram a funcionar mais cursos de formação de professores, a saber, os de Matemática, Ciências Sociais e Filosofia.

Neste artigo, relatamos parte dos resultados de uma pesquisa, que buscou responder à questão "Como se deu o processo de formação de professores de Matemática

\footnotetext{
${ }^{1}$ Em 21 de setembro de 1989, passados 27 anos da criação da FUNM, foi promulgado o texto constitucional do Estado de Minas Gerais que criou a Universidade Estadual de Montes Claros - Unimontes. A criação da Unimontes está registrada no parágrafo terceiro do artigo 82 do Ato das Disposições Constitucionais Transitórias (ADCT): "Fica transformada em autarquia, com a denominação de Universidade Estadual de Montes Claros, a atual Fundação Norte Mineira de Ensino Superior (MINAS GERAIS, 1989)".

2 O Polígono das Secas é um território reconhecido pela legislação como sujeito a períodos críticos de prolongadas estiagens. Recentemente as Áreas Susceptíveis à Desertificação - SAD passaram a ser denominadas, por força de convenções internacionais (Convenção de Nairobi), Semi-Árido Brasileiro. Compreende os estados do Piauí, Ceará, Rio Grande do Norte, Paraíba, Pernambuco, Alagoas, Sergipe, Bahia e extremo norte de Minas Gerais e do Espírito Santo. Informação disponível em <http://www.codevasf.gov.br>. Acesso em: 29 out. 2013.

${ }^{3}$ Conforme dados do IBGE, em 1960 a população do norte de Minas contava com 804.903 habitantes. Fonte: MINAS GERAIS, Fundação João Pinheiro. Anuário Estatístico do Nordeste. FJP: Belo Horizonte, 1994.
} 
na FUNM, primeira instituição de ensino superior na região de Montes Claros, norte de Minas Gerais, no período de 1960 a 1990"? Referimo-nos aqui a uma parte do período focalizado, os primeiros anos de existência do curso, de 1968 a 1978. No âmbito da história da instituição estabelecida nos anos 1960 e que se tornou uma universidade estadual em Minas Gerais, nosso trabalho aborda o curso de Matemática, devido a nosso interesse pela história da formação de professores responsáveis pela docência dessa disciplina no Brasil. A investigação mobilizou fontes de natureza diversificada, tais como documentos da Diretoria de Desenvolvimento de Recursos Humanos (DDRH) e da Secretaria Geral da Unimontes; propostas pedagógicas e programas das disciplinas do curso de Matemática no período em foco; periódicos editados pela Fafil e pela FUNM; jornais e legislação educacional da época; documentos produzidos por professores do curso, tais como diários de classe e planos de curso; acervo bibliográfico vinculado ao curso. No entanto, uma fonte central para a pesquisa foi constituída pelos depoimentos de sujeitos vinculados ao curso de Matemática estudado, no período focalizado. Usando a metodologia da História Oral, realizamos entrevistas com ex-alunos e antigos professores desse curso. Na próxima seção, discorremos sobre nossas fontes, dedicando-nos a considerações especiais sobre nossas perspectivas quanto aos depoimentos de nossos entrevistados.

\section{As fontes de nossa pesquisa e o protagonismo da História Oral}

Em nosso trabalho, não menosprezamos os documentos escritos relativos a diversas instâncias relacionadas ao curso investigado e buscamos construir articulações entre eles e os documentos resultantes de depoimentos orais. Todas as fontes foram analisadas, balizadas, interrogadas. Utilizamos documentos de âmbito nacional (analisamos pareceres, decretos, portarias do Ministério da Educação e Revistas Documenta - uma publicação do Conselho Federal de Educação), estadual (fizemos um estudo da Carta Constitucional Estadual, de leis estaduais e pareceres do Conselho Estadual de Educação), municipal (foram lidas deliberações de conselhos) e de segmentos da instituição estudada (atas de reuniões, regimento do Conselho Universitário, relatórios de gestão, Projeto Político Pedagógico do Curso de Matemática, Planos de Curso e Diários do Curso de Matemática), com o intuito de entender como as políticas públicas foram mobilizadas em prol da educação superior no tempo e espaço estudados.

Entretanto, enfatizamos que fontes essenciais mobilizadas por nós foram, como dissemos, os depoimentos de sujeitos ligados ao curso de Matemática da Unimontes no período alvo da pesquisa, que procuramos colocar em diálogo com o material documental referido acima.

Vemos a História Oral como uma metodologia importante a partir dos anos 1970, num cenário em que, segundo Amado e Ferreira (1996), os depoimentos, os relatos pessoais e as biografias foram revalorizados e muitos dos problemas de que eram acusados, relativizados. Essas autoras destacam, desde então, o desenvolvimento de argumentos em defesa da abordagem biográfica, no sentido de que "o relato pessoal pode assegurar a transmissão de uma experiência coletiva e constituir-se numa representação que espelha uma visão de mundo". (AMADO; FERREIRA, 1996, p. xxii).

Nessa perspectiva, ao ouvir os relatos de nossos colaboradores, tivemos como meta a recuperação da memória individual e coletiva, das informações sobre fatos não registrados, associando-os a eventos da vida pública e privada que nos revelam "visões" 
de mundo, dos lugares, da vida e da profissão. Tivemos a intenção de construir, conforme Garnica (2007, p. 21-22), "enunciações em perspectiva" mediante esses relatos, tendo a clareza de que, em nosso trabalho, a História Oral configurou-se como método de pesquisa qualitativo, permitindo-nos "trafegar por outras cercanias, ter outros interlocutores e vizinhos".

Não consideramos, todavia, que os relatos resultantes de uma pesquisa que tem como base a História Oral constituem-se na própria história que se quer contar, por almejarmos demarcar a ausência de uma confusão, de nossa parte, entre memória (cujo registro, a partir de captações da oralidade, gera fontes defendidas como legítimas pelos oralistas) e história - mais propriamente a Historiografia (resultado específico de uma hermenêutica disparada a partir de fontes disponíveis ou anteriormente criadas) (GARNICA; FERNANDES; SILVA, 2011). Nessa perspectiva, a entrevista é uma fonte que deve ser interpretada e não recebida como uma revelação do real, da verdade. A opção pela História Oral, porém, significa, como enfatiza Garnica (2010, p. 33):

afastar-se da perspectiva historiográfica positivista, o que implica fundamentalmente neutralizar concepções absolutistas que defendem a existência de uma "História verdadeira" e a possibilidade de aproximação congenial com os autores de textos (quaisquer que seja a natureza desses textos).

Galvão e Lopes (2010) alertam-nos que, embora muitos percebam a História Oral como uma forma simples de fazer história, ela nos propõe problemas, tais como a imprevisibilidade e o não controle da situação de entrevista, que demanda disposição e habilidade de escuta do pesquisador; a questão do retalhamento da voz dos sujeitos, necessária à operação historiográfica, mas que requer, na medida do possível, a inteireza dos depoimentos; o cruzamento de fontes, importante para minimizar o risco de considerar as entrevistas como "vozes" daqueles que não podem falar e para subsidiar a formulação das perguntas das entrevistas e a compreensão das respostas obtidas. Com essas diretrizes, procuramos compreender, interpretar e articular os depoimentos colhidos aos seus contextos de produção e atuar de modo semelhante em relação às outras fontes documentais.

Para a coleta dos depoimentos, tivemos em mente que os trabalhos construídos a partir da metodologia da História Oral estão fundamentalmente baseados na memória, entendida como uma construção erigida no presente com a consideração das experiências vivenciadas no passado. Nossos colaboradores foram escolhidos por terem sido alunos e, posteriormente, professores do curso de Matemática na instituição focalizada. Também foram colaboradoras de nossa pesquisa duas professoras, cofundadoras da Fafil, o primeiro professor da primeira turma do curso de Matemática dessa instituição e uma pedagoga, também professora do curso. Realizamos ao todo 15 entrevistas, com 16 colaboradores dois deles foram entrevistados juntos. Nossos entrevistados foram Dilma Silveira Mourão, Edson Crisóstomo dos Santos, Edson Guimarães, Francisco Bastos Gil, Isabel Rebello de Paula, João Barbosa de Souza, Juvenal Caldeira Durães, Maria de Lourdes Ribeiro Paixão, Maria Isabel Magalhães de Figueiredo Sobreira (Baby Figueiredo), Mariza Monteiro Guimarães, Ronaldo Dias Ferreira, Rosa Terezinha Paixão Durães, Rosina Rabelo Nuzzi Ribeiro, Ruth Tolentino Barbosa, Sebastião Alves de Souza e Wandaik Wanderley. 0 Quadro 01, a seguir, sintetiza algumas informações sobre nossos colaboradores. 
Quadro 01 - Colaboradores da pesquisa.

\begin{tabular}{|c|c|c|c|}
\hline $\begin{array}{l}\text { Nome do(a) } \\
\text { entrevistado(a) }\end{array}$ & $\begin{array}{c}\text { Ano em que se } \\
\text { formou/ ano em } \\
\text { que iniciou a } \\
\text { docência na } \\
\text { instituição }\end{array}$ & Vínculo com a instituição & $\begin{array}{l}\text { Data da } \\
\text { entrevista }\end{array}$ \\
\hline Dilma Silveira Mourão & $1976 / 1979$ & $\begin{array}{l}\text { Ex-aluna do Curso de Matemática e ex- } \\
\text { professora }\end{array}$ & 03/12/2012 \\
\hline $\begin{array}{l}\text { Edson Crisóstomo dos } \\
\text { Santos }\end{array}$ & $1988 / 1996$ & $\begin{array}{l}\text { Ex-aluno do Curso de Ciências com } \\
\text { habilitação em Matemática e atual } \\
\text { professor }\end{array}$ & $13 / 06 / 2013$ \\
\hline Edson Guimarães & 1971 & $\begin{array}{l}\text { Ex-aluno e um dos fundadores do curso de } \\
\text { Matemática da Fafil }\end{array}$ & $28 / 05 / 2013$ \\
\hline Francisco Bastos Gil & 1968 & $\begin{array}{l}\text { Graduado em Matemática. Ex-professor e } \\
\text { um dos fundadores do curso de } \\
\text { Matemática da Fafil }\end{array}$ & 03/07/2013 \\
\hline Isabel Rebello de Paula & 1968 & $\begin{array}{l}\text { Graduada em História. Ex-diretora da Fafil, } \\
\text { ex-professora (do curso de História) e uma } \\
\text { das fundadoras da Fafil }\end{array}$ & $24 / 01 / 2014$ \\
\hline João Barbosa de Souza & 1979/1995 & $\begin{array}{l}\text { Ex-aluno do Curso de Matemática e atual } \\
\text { professor }\end{array}$ & $28 / 05 / 2013$ \\
\hline Juvenal Caldeira Durães & $1971 / 1972$ & $\begin{array}{l}\text { Ex-aluno, ex-professor e um dos } \\
\text { fundadores do curso de Matemática da } \\
\text { Fafil }\end{array}$ & $29 / 10 / 2012$ \\
\hline $\begin{array}{l}\text { Maria de Lourdes Ribeiro } \\
\text { Paixão }\end{array}$ & 1968 & Graduada em Pedagogia. Ex-professora & $23 / 05 / 2013$ \\
\hline $\begin{array}{l}\text { Maria Isabel Magalhães } \\
\text { de Figueiredo Sobreira } \\
\text { (Baby Figueiredo) }\end{array}$ & 1968 & $\begin{array}{l}\text { Graduada em Pedagogia. Ex-professora e } \\
\text { uma das fundadoras da Fafil }\end{array}$ & 02/07/2013 \\
\hline $\begin{array}{l}\text { Mariza Monteiro } \\
\text { Guimarães }\end{array}$ & $1971 / 1972$ & $\begin{array}{l}\text { Ex-aluna, ex-professora e uma das } \\
\text { fundadoras do curso de Matemática da } \\
\text { Fafil }\end{array}$ & $28 / 05 / 2013$ \\
\hline Ronaldo Dias Ferreira & 1992/1993 & $\begin{array}{l}\text { Ex-aluno do Curso de Matemática e atual } \\
\text { professor }\end{array}$ & $20 / 05 / 2013$ \\
\hline $\begin{array}{l}\text { Rosa Terezinha Paixão } \\
\text { Durães }\end{array}$ & $1971 / 1972$ & $\begin{array}{l}\text { Ex-aluna, ex-professora e uma das } \\
\text { fundadoras do curso de Matemática da } \\
\text { Fafil }\end{array}$ & $28 / 11 / 2012$ \\
\hline $\begin{array}{l}\text { Rosina Rabelo Nuzzi } \\
\text { Ribeiro }\end{array}$ & $1977 / 1978$ & $\begin{array}{l}\text { Ex-aluna do Curso de Matemática e atual } \\
\text { professora }\end{array}$ & 04/06/2013 \\
\hline Ruth Tolentino Barbosa & $1975 / 1976$ & $\begin{array}{l}\text { Ex-aluna e ex-professora do Curso de } \\
\text { Matemática }\end{array}$ & 03/12/2012 \\
\hline $\begin{array}{l}\text { Sebastião Alves de } \\
\text { Souza }\end{array}$ & $1989 / 1997$ & $\begin{array}{l}\text { Ex-aluno do Curso de Ciências com } \\
\text { habilitação em Matemática e atual } \\
\text { professor }\end{array}$ & $21 / 05 / 2013$ \\
\hline Wandaik Wanderley & $1971 / 1972$ & $\begin{array}{l}\text { Ex-aluno, ex-professor e um dos } \\
\text { fundadores do curso de Matemática da } \\
\text { Fafil }\end{array}$ & $25 / 06 / 2013$ \\
\hline
\end{tabular}

Fonte: Elaboração das autoras a partir das entrevistas realizadas em 2012 e 2013. 
As entrevistas foram transcritas e, em seguida, procedemos a sua textualização, isto é, cada transcrição foi transformada em uma versão editada, na qual tivemos a intenção de organizar as ideias numa sequência lógica e retiramos os chamados "vícios" de linguagem e as afirmações repetidas. Ao mesmo tempo, tivemos como horizonte preservar o tom das narrativas de modo que nossos colaboradores se reconhecessem nas textualizações. Percebemos o resultado como uma construção conjunta, para a qual contribuíram as análises, trocas de ideias, supressões e acréscimos de entrevistado e pesquisador ${ }^{4}$.

É importante destacar que alguns de nossos entrevistados nos solicitaram tempo para que empreendessem uma revisão e um ajustamento na linguagem das respectivas narrativas textualizadas no sentido de buscar expressões que julgavam mais apropriadas para caracterizar sua fala. Especialmente as textualizações dos professores Juvenal Caldeira Durães, Isabel Rebello de Paula e Maria Isabel (Baby) de Magalhães Figueiredo Sobreira passaram por um processo de reedição, por esses entrevistados acreditarem que o texto inicialmente apresentado poderia ser reelaborado de maneira mais próxima de seus estilos pessoais de narrativa. Cabe aqui a reflexão proposta por Bourdieu (2006) acerca da "ilusão biográfica": é essencial contextualizar a ação do sujeito numa "superfície social" marcada por uma pluralidade de campos em momentos distintos, ou seja, em seus relatos, nossos colaboradores tiveram a preocupação de dar sentido, de construir uma lógica retrospectiva e prospectiva, consistente e constante sobre suas ações, constituindo relações inteligíveis para cada etapa do desenvolvimento necessário de suas histórias e de suas contribuições para a criação e o estabelecimento da instituição que veio a ser a Unimontes. Nesses relatos, que deixam entrever, também, uma ilusão retórica, são produzidas histórias de vida e a vida é tratada como uma história, por meio de um registro coerente de acontecimentos em sequência, com significado e direção. Seguindo com Bourdieu, os nomes de nossos entrevistados revelam "uma identidade social constante e durável, que garante a identidade do indivíduo biológico em todos os campos possíveis onde ele intervém como agente, isto é, em todas as suas histórias de vida possíveis". (BOURDIEU, 2006, p. 188, grifo do autor).

Portanto, esse movimento narrativo empreendido por nossos depoentes nos leva a crer que seus relatos aproximam-se da apresentação oficial de si, ou seja, da produção de si, que conduz a uma "pulsão narcísica socialmente reforçada" (BOURDIEU, 2006, p. 191), como sujeitos imprescindíveis àquela época, àquele lugar, àquelas funções. $O$ que observamos na reformulação dos textos por alguns de nossos entrevistados foi a preocupação em realçar mais menções a datas e fatos do que ao cotidiano e às ações dos sujeitos, com a produção de um discurso racional, organizado, cuidadoso.

Convém esclarecer que respeitamos as ideias, as opiniões, as alterações e, ainda, acatamos a manutenção das narrativas como melhor pareciam aos nossos colaboradores, atentando, em nossa análise, nas subjetividades e percepções particulares, colocando-as num mesmo nível de importância das fontes escritas mais clássicas, também fundamentais a esse processo de narrar. Percebemos a existência de depoimentos cuidadosos que apontam delicada e diplomaticamente a existência de conflitos entre os grupos envolvidos

\footnotetext{
${ }^{4}$ Cumpre esclarecer que todos os nossos colaboradores assinaram documentos nos quais autorizaram a divulgação de seus nomes e cederam a nós os direitos quanto às gravações, transcrições e textualizações de suas entrevistas.
} 
no processo de criação da instituição focalizada e, posteriormente, do curso de Matemática, enquanto que, em outras narrativas, as divergências e os conflitos são explicitados como algo natural, inerente aos processos de formação humana e institucional.

\section{Em meio à carência e à urgência cria-se um curso de Matemática}

Como ressaltamos no início deste texto, na região de Montes Claros, na década de 1960, evidenciavam-se problemas de ordem educacional, caracterizados pela insuficiência de instituições escolares e de docentes qualificados para atender às necessidades da população. Os primeiros cursos estabelecidos na Fafil visavam a essa demanda, e, como foi dito, a formação de professores de Matemática passou a ser realizada na instituição em 1968. Esse curso de licenciatura foi autorizado pelo Parecer № 45 do Conselho Estadual de Educação de Minas Gerais, em 19 de abril desse ano, mas só foi legitimado oficialmente no cenário brasileiro a partir do Decreto Federal 74650/74, de 7 de outubro de 1974, que concedeu reconhecimento à Faculdade de Filosofia, Ciências e Letras do Norte de Minas, mantida pela Fundação Norte Mineira de Ensino Superior e sediada em Montes Claros.

A carência acentuada de profissionais habilitados em Matemática para lecionar nas escolas secundárias da região naquele momento foi sublinhada pelos depoentes de nossa pesquisa, que destacaram as dificuldades em relação à formação de um corpo de profissionais qualificados para atuar nesse nível de ensino, bem como no nível superior, nos anos 1964-1968; pesava nesse contexto o fato de o município de Montes Claros ser geograficamente distante das instituições que formavam esses profissionais. A professora Baby Figueiredo (Entrevista, 02/07/2013), uma das fundadoras da Fafil, salientou que $O$ curso de Matemática [...] surgiu em razão de uma grande demanda dos professores que lecionavam a disciplina em colégios públicos e necessitavam de capacitação e do grau de licenciatura para efeito de promoção na carreira docente 5 . Nas palavras do professor Wandaik Wanderley (Entrevista, 25/06/2013), ex-aluno, ex-professor e um dos fundadores do curso, não havia nenhum professor de Matemática, com o curso, formado... eram poucas pessoas que sabiam Matemática... quem dirá com o curso de Matemática... De acordo com o professor Edson Guimarães (Entrevista, 28/05/2013), também ex-aluno e fundador do curso, a falta de um curso de licenciatura em Matemática, na década de 1960, era um "grande problema".

Nós tínhamos a Fundação Norte Mineira de Ensino Superior (FUNM) com cursos de Pedagogia, Letras, Geografia e História. Mas não havia o curso de Matemática. Então, aqui em Montes Claros, nós fizemos uma reunião... [...] Nós fomos até à Fundação... Nós, professores de Matemática leigos, tínhamos a autorização para lecionar. Nós organizamos um grupo e solicitamos que... [...] Então nós fizemos a solicitação junto à FUNM para a criação do curso de Matemática. (Professor Edson Guimarães, Entrevista, 28/05/2013).

A professora Ruth Tolentino (Entrevista, 03/12/2012), ex-aluna e ex-professora do curso, fez coro às narrativas anteriores, chamando a atenção para o exercício da docência em Matemática, na época, por profissionais com outras habilitações.

O surgimento do curso foi por uma questão de demanda e necessidade da região... A falta de professor de Matemática nas escolas... Na verdade, quem dava as aulas de Matemática, nessa época, eram os engenheiros. Em toda a região do Norte de Minas não

${ }^{5}$ Para efeito de destaque, os trechos de falas de nossos entrevistados são apresentados em itálico. 
havia professor de Matemática. Formados em Matemática mesmo, não! (Professora Ruth Tolentino, Entrevista, 03/12/2012).

Juntamente com os resultados de outras pesquisas sobre a formação de professores de Matemática (BARALDI, 2003; CURY, 2011; FERNANDES, 2011; MARTINS-SALANDIM, 2012), esses trechos das narrativas de nossos entrevistados convergem em relação à presença constante de um cenário de carências e urgências na instalação dos cursos de Matemática criados no país a partir da década de 1960 (GARNICA, 2010). A urgência estava vinculada a uma exigência legal de que os professores tivessem a habilitação mínima obtida em instituições de ensino superior. E a carência se dava pela falta de sujeitos com certificação para atuar no ensino secundário, pois os que até então atuavam não eram habilitados para o exercício da função.

Na pesquisa documental que realizamos, constatamos que a Reforma Capanema (Lei Orgânica do Ensino Secundário oㅡ 4.244 de 9 de abril de 1942) acentuou a carência de professores em virtude da significativa expansão do ensino secundário, o que concorreu para a elevação do número de instituições desse nível de ensino e, consequentemente, do número de matrículas em todo o território nacional. Portanto, foram repercussões diretas da expansão a carência de docentes qualificados e certificados para lecionar e a urgência de contar com professores suficientes para as turmas criadas. Os professores eram "superutilizados" e, em decorrência das demandas, muitos outros foram submetidos a exames de suficiência e frequentaram os cursos da Cades - Campanha de Aperfeiçoamento e Difusão do Ensino Secundária para se habilitarem legalmente ao exercício da docência. O Decreto Lei oㅡ 8.777, de 22 de janeiro de 1946, dispunha sobre o registro definitivo de professores de ensino secundário, após sua aprovação em tais exames, no Ministério da Educação e Saúde. No mesmo sentido, inseriu-se também, muito depois, a Lei $n^{0} 2.430$ de 19 de fevereiro de 1955, que regulamentava a realização dos exames de suficiência do magistério nos cursos secundários.

A Cades foi instituída como uma ação emergencial do governo Getúlio Vargas por meio do Decreto oㅜ 34.638, de 14 de novembro de 1953, com o duplo objetivo de elevar o nível do ensino secundário e difundi-lo. Essa campanha visava ao preparo técnico de profissionais para o exercício de diversas funções ligadas ao funcionamento das escolas secundárias, e entre tais funções tinha destaque a formação de professores.

Seis dos nossos depoentes - Juvenal Caldeira Durães, Rosa Terezinha Paixão Durães, Edson Guimarães, Mariza Monteiro Guimarães, Ruth Tolentino Barbosa e Dilma Silveira Mourão - participaram dos cursos da Cades. A seguir, apresentamos excertos de

\footnotetext{
${ }^{6}$ Com o intuito de verificar a existência de outros cursos de Matemática na região norte-mineira no período de 1960 a 1970, fizemos uma minuciosa consulta aos exemplares da revista Documenta, uma publicação mensal do Conselho Federal de Educação. Verificamos que, no norte de Minas, especificamente em Montes Claros, a Fafil foi a única instituição a solicitar autorização para funcionamento de um curso de Matemática na década de 1960. Na década de 1970, identificamos a solicitação de reconhecimento de cursos de Matemática em Minas Gerais e em outras regiões/municípios do país, como por exemplo: da Universidade Federal de Juiz de Fora (Minas Gerais) - Parecer no 3.268/74; da Faculdade de Filosofia, Ciências e Letras do Instituto Cultural Newton Paiva Ferreira (Minas Gerais) - Parecer no 3.253/74; da Faculdade de Filosofia, Ciências e Letras São Judas Tadeu do Instituto Alberto Mesquita de Camargo (São Paulo) - Parecer no 3.203/74); da Faculdade de Filosofia, Ciências e Letras Rui Barbosa da Sociedade Cultural de Andradina (São Paulo) - Parecer no 3.225/74; da Faculdade de Filosofia, Ciências e Letras de Moema da Sociedade Brasileira de Educação de Assistência (São Paulo) - Parecer no 3.240/74. No volume 167, publicado em outubro de 1974, consta o Decreto de Reconhecimento da Fafil, no qual há referência aos cursos de Ciências Sociais, Matemática e Filosofia.
} 
algumas de suas entrevistas nos quais são comentados aspectos dos cursos da Cades e é ressaltada a sua importância para o exercício da docência no ensino secundário.

Antes de me formar, dei aulas de Matemática no Ginásio do Menor. Depois que me formei, trabalhei, também, além da Faculdade, na E. E. Profa. Dulce Sarmento. Tive que participar dos cursos da Campanha de Aperfeiçoamento e Difusão do Ensino Secundário (Cades) durante dois ou três anos. (Professora Ruth Tolentino, Entrevista, 03/12/2012).

O objetivo do curso era dar sustentação aos profissionais leigos que lecionavam nas escolas. Também tinha os Cursos da Campanha de Aperfeiçoamento e Difusão do Ensino Secundário (Cades). Era uma formação que o Estado dava para os professores, um treinamento anual. (Professor Edson Guimarães, Entrevista, 28/05/2013).

Quem trabalhava com a disciplina Matemática e não tinha a licenciatura, que era o meu caso, deveria fazer o curso da Campanha de Aperfeiçoamento e Difusão do Ensino Secundário (Cades) durante todo o mês de janeiro, todo ano, lá em Belo Horizonte. Isso era para provimento da cadeira de Matemática. Eu comecei a fazer o curso em 1966, quando iniciei minha atuação como professora de Matemática. A gente não era habilitada para lecionar Matemática, mas quem conseguisse fazer o exame de suficiência lá em Belo Horizonte... (Professora Dilma Silveira Mourão, Entrevista, 03/12/2012).

Os depoimentos sintonizam-se aos argumentos de Baraldi e Gaertner (2013) de que, até o final dos anos 1970, a Cades serviu à educação brasileira realizando cursos de formação de professores para o ensino secundário, bem como de preparação de outros profissionais da educação: diretores, orientadores educacionais, inspetores, secretários escolares ${ }^{7}$. Vale ressaltar que os cursos da Cades se realizavam, intensamente, no período de férias dos professores, ou seja, nos meses de janeiro e fevereiro, a fim de não haver conflito com o período letivo. É também fundamental sublinhar que, de posse do registro de professor, os docentes regularizavam sua situação funcional e podiam prestar concurso e ingressar, oficialmente, na carreira de magistério do Estado de Minas Gerais. Isso aconteceu com as professoras Rosa Terezinha e Dilma, que, posteriormente, deram continuidade à sua formação no curso de licenciatura em Matemática da Fafil.

Onze de nossos colaboradores foram estudantes desse curso que, no futuro, se tornaram seus professores ainda enquanto alunos ou pouco depois de formados. Destacamos que oito dos dezesseis graduados da primeira turma foram convidados a atuar como professores das turmas posteriores; das turmas seguintes, formadas até a década de 1990, seis de nossos entrevistados tornaram-se professores do curso. São elucidativos alguns dos depoimentos quanto à carência de docentes para o próprio curso que pretendia suprir a carência de professores de Matemática na região de Montes Claros.

Para dar continuidade ao curso, depois da etapa de formação inicial, foram aproveitados pela Fafil, após a colação de grau, alguns alunos, como eu para lecionar Álgebra; Rosa, Estatística e José Soares, Física. [...] Passamos a ser os professores das turmas que nos seguiram e, também, de alguns dos nossos ex-colegas que ficaram para trás. Os nossos melhores alunos foram sendo aos poucos aproveitados e nos sucedendo nas nossas aposentadorias: Ruth Tolentino, Rosina Nuzzi, Cleusa dos Santos, Chiquita Tolentino, Rosivaldo Gonçalves, Edson Crisóstomo, Rômulo Barbosa, Sebastião Alves,

\footnotetext{
7 Devemos salientar, ainda, que a Cades publicou obras específicas para a formação dos docentes do ensino secundário.
} 
Dilma Mourão, João Barbosa e outros que se destacaram, aperfeiçoaram com especialização, mestrado e doutorado. (Professor Juvenal Caldeira Durães, Entrevista, 29/10/2012).

Fui ao mesmo tempo acadêmica e professora do curso porque, na época, meus professores eram muito sobrecarregados... Meus professores foram os primeiros licenciados na época, porque não existia professor licenciado. Então, eles me pediam para substituí-los e eu ia, eu dava aula para os acadêmicos; no segundo ano eu já dava aula para os alunos do primeiro ano. Ministrava todas as disciplinas que precisassem. Eles me pediam e eu dava aula no lugar deles, mas eu não tinha contrato com a FUNM, não. Era voluntária. (Professora Rosina Rabelo Nuzzi Ribeiro, Entrevista, 04/06/2013).

Percebemos, então, que outro aspecto da carência residia na própria instituição superior, que não tinha professores habilitados para lecionar em seus cursos. Essa não é uma característica exclusiva do curso de Matemática criado em Montes Claros, pois pode ser identificada em trabalhos sobre a formação de professores de Matemática em outras regiões do Brasil, como os anteriormente mencionados neste texto. O aspecto mais visível da carência da instituição estudada em relação à formação de professores de Matemática é que, logo que o curso de Matemática foi implantado, não havia, na região, professores que pudessem se responsabilizar pelas disciplinas matemáticas de maior peso na proposta curricular autorizada pelo Conselho Estadual de Educação, mediante seu Parecer no 45/68, para funcionamento do curso. A direção da Fafil, para solucionar o problema no primeiro momento, recorreu à importação de um docente de Belo Horizonte, o professor Francisco Bastos Gil. Essa medida revela a preocupação quanto ao estabelecimento de um padrão considerado de boa qualidade, enfatizada nos depoimentos de entrevistados de destaque nos primórdios do curso, como as professoras Baby Figueiredo e Maria de Lourdes Ribeiro Paixão e os professores Wandaik Wanderley e Juvenal Caldeira Durães.

Foi necessário contratar colegas de Belo Horizonte. Francisco Bastos Gil, matemático muito inteligente e capaz, dedicou-se integralmente ao curso, ministrando todas as disciplinas básicas: Física, Matemática, Geometria e outras; João Carlos Sobreira, arquiteto-urbanista, era responsável por Desenho Geométrico. (Professora Baby Figueiredo, Entrevista, 02/07/2013).

Passamos uma lista de adesão ao curso e fomos atrás de Francisco Bastos Gil que era de Belo Horizonte, mas que à época estava em São João del Rei, onde era aspirante do Exército - para dar início ao curso. Ele aceitou o nosso convite e veio para Montes Claros, para nos atender, começar uma nova vida e uma nova profissão. Era recémformado em Matemática pela Faculdade de Filosofia, Ciências e Letras de Belo Horizonte. (Professor Juvenal Caldeira Durães, Entrevista, 29/10/2012).

Informaram que o Gil estaria em condição de vir para cá. Fui atrás dele em Belo Horizonte. [...] Ele já tinha uma outra promessa, de um outro emprego, mas nós fizemos uma proposta melhor... Ele veio para cá e não se arrependeu. Ele ministrava quase todas as disciplinas. Havia mais uns três ou quatro professores. É isso. (Professor Wandaik Wanderley, Entrevista, 26/06/2013).

Como funcionou o curso no princípio de sua implantação? Qual era sua proposta curricular e como foi realizada na prática? Como se relacionavam alunos, professores de disciplinas? Qual era o perfil dos alunos e quantos se formaram nos primeiros anos? De que modo se pensava a formação matemática e pedagógica dos futuros licenciados? São 
essas as questões tratadas nas próximas seções.

\section{Os primórdios do curso de Matemática da Fafil: a proposta curricular e o corpo docente}

A proposta de estrutura curricular para o curso de Matemática foi elaborada em 1968, quando foi formalizado um requerimento ao Conselho Estadual de Educação, com data de 06/03/1968, pelo presidente da Fundação Universidade Norte Mineira. A carga horária prevista era de 2720 horas-aula, a serem cumpridas em quatro anos de duração, com a seguinte distribuição:

- 1ำ ano: Desenho Geométrico (60 horas), Geometria Analítica (140 horas), Cálculo Diferencial e Integral (180 horas), Álgebra (150 horas), Fundamentos de Matemática Elementar (120 horas);

- $2^{\circ}$ ano: Geometria Descritiva (90 horas), Cálculo Diferencial e Integral (180 horas), Geometria Analítica (180 horas), Fundamentos de Matemática Elementar (120 horas);

- 3a ano: Didática (90 horas), Cálculo Diferencial e Integral (180 horas), Geometria Analítica (150 horas), Cálculo Numérico (180 horas), Física Geral (120 horas);

- 4 ano: Física Geral (180 horas), Estatística (150 horas), Psicologia da Educação: Adolescência, Aprendizagem (90 horas), Elementos de Administração Escolar (90 horas), Prática de Ensino (120 horas).

Pode-se observar que não mais era seguido o esquema $3+1$ (estabelecido pelo Decreto $\mathrm{n}^{-1} 1.190$ de 1939, tanto para os cursos de licenciatura quanto para o curso de Pedagogia), no qual os três primeiros anos eram destinados a uma formação para o bacharelado e o último ano à preparação específica para a licenciatura ${ }^{8}$. Nota-se, no entanto, que a proposta apresentada ao Conselho Estadual de Educação concentrava nos três primeiros anos do curso as disciplinas de conteúdo específico de Matemática e Física. No $3^{\circ}$ ano, havia apenas uma disciplina pedagógica - Didática -, situando-se as demais no último ano. Três dessas disciplinas eram mais gerais (Didática, Psicologia da Educação e Elementos de Administração Escolar) e apenas uma se destinava especificamente aos futuros professores de Matemática, a Prática de Ensino.

O curso de Matemática da Fafil de Montes Claros acatou literalmente as prescrições legais que estabeleceram o seguinte currículo mínimo para a licenciatura em

\footnotetext{
8 Com a extinção legal do modelo 3+1, a partir da Lei de Diretrizes e Bases da Educação Nacional de 1961, houve a separação de bacharelado e licenciatura (CASTRO, 1974), registrada em pareceres do Conselho Federal de Educação nos quais "já não mais se admitia o esquema de três anos de bacharelado mais um de didática. Licenciatura e bacharelado passam a ser graus obtidos paralelamente, a partir de disciplinas comuns" (CASTRO, 1974, p. 638). Essa recomendação pode ser verificada no número 10 da revista Documenta, em que os Pareceres registrados estabelecem o mínimo de disciplinas pedagógicas para as licenciaturas:

1. Psicologia da Educação; Adolescência, Aprendizagem.

2. Elementos de Administração Escolar.

3. Didática.

4. Prática de Ensino, sob forma de estágio supervisionado

(BRASIL. DOCUMENTA no 10, 1962, p. 99).
} 
Matemática, a ser integralizada em quatro anos:

1. Desenho Geométrico e Geometria Descritiva

2. Fundamentos de Matemática Elementar

3. Física Geral

4. Cálculo Diferencial e Integral

5. Geometria Analítica

6. Álgebra

7. Cálculo Numérico

8. Matérias pedagógicas de acôrdo com o Parecer n.o 292 aprovado em Nov. de 1962

(BRASIL. DOCUMENTA no 10, 1962, p. 85-86).

Como foi comentado antes, a necessidade de oferecer um número grande de disciplinas matemáticas logo no início do curso conduziu à contratação do professor Francisco de Bastos Gil, que se responsabilizou por todas elas. Disse o professor Gil (Entrevista, 03/07/2013): Comecei a dar o curso... Não tinha professor para nenhuma disciplina, eu dava aula de Cálculo, Fundamentos, Geometria Analítica... Dava aula de tudo... Um dos alunos da primeira turma, o professor Juvenal Caldeira Durães (Entrevista, 29/10/2012), corroborou a fala: Gil, como já foi dito, foi nosso professor durante todo o curso e lecionou Cálculo Integral e Diferencial, Cálculo Numérico, Fundamentos Matemáticos. O professor João Barbosa de Souza, também aluno da primeira turma do curso, reiterou a atuação polivalente do professor Gil e destacou que os próprios alunos atuavam como professores de turmas em nível anterior ao que estavam cursando: Ele segurava o curso e outros professores, que eram alunos de anos mais adiantados, davam aulas pra gente. Era praticamente colega dando aula pra colega. A carência de professores era muito grande. (Professor João Barbosa de Souza, Entrevista, 28/05/2013).

Além do professor Francisco Gil, compunham o corpo docente do curso de Matemática da Fafil nos anos 1960 e 1970 um professor de Desenho Geométrico, graduado em Arquitetura, e professores recém-formados em Pedagogia e Letras, da cidade de Montes Claros; uma professora graduada em Pedagogia, do município vizinho de Bocaiúva. Os professores obtinham autorização para lecionar no curso mediante a aprovação de seus nomes pelo Conselho Federal de Educação (CFE). A professora Maria de Lourdes Ribeiro Paixão, que também residia em outro município, foi convidada a assumir as aulas de Didática Geral e, ainda, a dar suporte pedagógico aos cursos da Fafil. Maria de Lourdes (Entrevista, 23/05/2013) disse: Vim pra Montes Claros em 1968. O corpo docente da FUNM era formado, em sua maioria, de professores recém-formados da UFMG. Comecei trabalhando com Didática Geral. Como pedagoga e professora de didática da primeira turma... [...] No caso específico de Didática, eu tinha uma segurança muito grande e como eu sempre fui apaixonada por matemática eu gostava de estudar com eles, de pesquisar e de descobrir novas formas para trabalhar o conteúdo. (Professora Maria de Lourdes Ribeiro Paixão, Entrevista, 23/05/2013).

Deve-se ressaltar que a Fafil, para atender à necessidade de oferecimento das disciplinas pedagógicas do novo curso de Matemática, pôde contar com os docentes que as lecionavam nos cursos de licenciatura criados anteriormente, os de Letras, Pedagogia, Geografia e História.

A professora Mariza Guimarães (Entrevista, 28/05/2013), estudante da primeira turma, lembrou-se ainda da disciplina Organização Social e Política do Brasil (OSPB), 
implantada nos currículos no período da ditadura militar, que era ministrada na Igreja Matriz da cidade: Mas não era só para o nosso curso, não! Era para a Faculdade toda. Quem dava as aulas de OSPB era o padre Jorge Ponciano, que veio de Brasília. A Igreja ficava lotada. Segundo Cunha (2012), desde o fim do século XIX os meios militares brasileiros defendiam uma intervenção na educação pública no sentido de regeneração moral da sociedade. Nesse sentido, no início da década de 1960, com a intensificação da crise de hegemonia e o acirramento da Guerra Fria, a Educação Moral e Cívica, sob diferentes denominações, era cada vez mais proposta pelos conservadores e especialmente pela direita como um componente educacional solucionador para o que se denominava "a crise brasileira". A defesa principal da inserção obrigatória dessa disciplina, do ensino primário ao superior, era feita pela Escola Superior de Guerra. Depois do golpe de Estado de 1964, o que era proposta se transformou em política de governo, para a qual houve, inicialmente, resistência da parte do Conselho Federal de Educação. Contudo, depois do Ato Institucional n‥ 5, essa resistência ruiu diante da pressão direta da ditadura. Em 12 de setembro de 1969, a junta militar que governava o país em decorrência do afastamento do general-presidente Costa e Silva por motivos de saúde e da deposição do vice-presidente Pedro Aleixo baixou o decreto-lei no 869 , visando à inserção obrigatória da disciplina Educação Moral e Cívica nos currículos de todos os graus e modalidades de ensino do país. No ensino superior, essa disciplina foi mais comumente chamada Estudos de Problemas Brasileiros (EPB) e sua implantação variou muito entre as instituições: algumas procuraram a colaboração de oficiais das Forças Armadas e de civis ex-alunos dos cursos da Escola Superior de Guerra, enquanto outras utilizavam seus próprios quadros docentes, com diferentes opções ideológicas, o que resultava em distintas visões quanto à natureza daqueles problemas. $\mathrm{A}$ professora Mariza referiu-se de forma geral às disciplinas que pretendiam veicular moral e civismo no ensino superior no período da ditadura pela sigla OSPB; conjeturamos que, no caso do curso de Matemática da Fafil, tratava-se da disciplina Estudos de Problemas Brasileiros. A narrativa de Mariza mostra que o docente responsável por ela era um sacerdote católico vindo de Brasília, o que revela uma solução local encontrada pela instituição de Montes Claros sintonizada com o quadro geral de diversificação na implementação da disciplina apresentado no texto de Cunha (2012).

Um aspecto muito importante nos primeiros anos do curso de licenciatura em Matemática da Fafil, indicado tantos nos depoimentos dos entrevistados quanto nos documentos escritos, foi a criação, na mesma instituição, em 1972, de outro curso, o de licenciatura curta em Ciências - $1^{\circ}$ grau, com duração de dois anos e meio. Os cursos de Ciências $-1^{\circ}$ grau e Matemática funcionaram simultaneamente durante alguns anos até que, em 1978, em cumprimento ao Decreto Federal o 82.371/78, de 04/08/78, houve a fusão de ambos. A licenciatura em Matemática, que tinha duração de quatro anos, passou a denominar-se "Ciências". A partir daí, passaram a ser oferecidas 80 (oitenta) vagas para ingresso no curso, com as opções de os acadêmicos o concluírem em dois anos e meio, obtendo, desse modo, a licenciatura curta em Ciências do $1^{\circ}$ grau, ou darem continuidade aos estudos por mais um ano e meio e obterem a habilitação em Matemática ou em Biologia.

Neste artigo, como dito anteriormente, abordamos somente o período em que existiu na Fafil o curso de licenciatura em Matemática de quatro anos, os seja, de 1968 a 1978. A seguir, discorremos sobre o perfil dos alunos das primeiras turmas desse curso e 
sua formação acadêmica nele.

\section{Os alunos das primeiras turmas da licenciatura em Matemática e sua formação acadêmica: a força dos conteúdos matemáticos}

Os estudantes do curso de licenciatura em Matemática das primeiras turmas eram das regiões norte e nordeste de Minas Gerais (especificamente dos municípios de Almenara, Bocaiúva, Brasília de Minas, Buenópolis, Coração de Jesus, Diamantina, Francisco Sá, Guanhães, Janaúba, Januária, Jequitaí, Juramento, Mirabela, Monte Azul, Oliveira, Palmópolis, Paracatu, Pirapora, Piumbi, Rio Pardo de Minas, Tiros, Várzea da Palma $)^{9}$, o que está de acordo com a afirmativa de muitos entrevistados de que a Faculdade de Filosofia, Ciências e Letras (Fafil) e, posteriormente, a Fundação Norte Mineira de Ensino Superior (FUNM) tinham alcance regional.

Uma característica do perfil desses alunos é que já exerciam outras atividades durante o dia, ou seja, já trabalhavam como docentes e/ou atuavam profissionalmente no comércio, em bancos e empresas. Como foi acentuado, muitos dos primeiros alunos do curso eram professores de Matemática nas escolas da região em busca da certificação necessária para continuarem a exercer a profissão. A primeira turma formou poucos alunos. De acordo com o professor Juvenal

Começamos, em 1968, com 64 alunos distribuídos em duas turmas (uma à tarde e outra à noite) e terminamos com uma à noite, com apenas 16 formandos em 1971. Os outros se perderam no decorrer do curso. (Professor Juvenal Caldeira Durães, Entrevista, 29/10/2012).

Nossos entrevistados, várias vezes, procuraram caracterizar sua situação de estudantes que, ao mesmo tempo, exerciam a profissão de professores.

Estudei com bastante dificuldade porque eu trabalhava lá em Bocaiúva e não havia estrada. Estava começando a melhorar a estrada. Então a gente passava por um desvio. Eu vinha mais no final de semana... Vinha na sexta e assistia às aulas na sexta e no sábado. Pegava a matéria dada e estudava sozinha. Os professores consideravam muito as dificuldades que a gente tinha... Nós não tivemos estágio porque já éramos professores. Então, eles não cobravam estágio, não. (Professora Mariza Monteiro Guimarães, Entrevista, 28/05/2013).

Nós tínhamos essas regalias... As outras turmas da graduação, Geografia, História, Português, se sentiam lesadas, porque só a turma de Matemática tinha esse privilégio de ir à aula no dia em que fosse possível. Nós éramos professores e isso foi muito considerado... (Professor Edson Guimarães, Entrevista, 28/05/2013).

O professor Gil via minha dificuldade para vir estudar. Ele me avisava quando ia acontecer alguma reunião para eu não vir. Uma coisa que ajudou muito, no curso de Matemática, foi que os professores não ficavam naquela cobrança do aluno estar presente... Muitos nem faziam chamada... Se você tinha um bom desempenho, ficava tranquilo... Então, geralmente, eu vinha umas três vezes por semana. (Professora Dilma Silveira Mourão, Entrevista, 03/12/2012).

As narrativas de nossos colaboradores revelam os privilégios e as regalias que

\footnotetext{
${ }^{9}$ Conforme os Livros de Registro de Matrícula - 1968 a 1975 - arquivados na Secretaria Geral da Unimontes. Nota-se, também, a presença de estudantes de outros estados: Bahia, São Paulo e Rio Grande do Norte.
} 
aqueles que já atuavam como professores do ensino primário e/ou secundário tinham em relação aos outros acadêmicos: possibilidade de se ausentar das aulas nos momentos de trabalho formal e autonomia/oportunidade para fazer os trabalhos e exercícios aplicados em sala em outro momento e espaço. O fato de exercerem o ofício docente lhes conferia um status diferenciado, certa autoridade moral e profissional perante seus professores e demais colegas e, ainda, sua experiência na função os desobrigava de realizar o estágio curricular do curso. É interessante a visão do professor Francisco Bastos Gil sobre a primeira turma:

Da turma inicial, não me lembro mais quantos concluíram, mas parece que foram uns quinze ou dezesseis, mais ou menos, que conseguiram formar, dos cinquenta $e$ tantos... Mas, em compensação, formaram dezesseis professores com $P$ maiúsculo. Eu "botava a mão no fogo por eles", porque, para falar a verdade, as nossas provas eram muito mais difíceis do que as que eu fazia aqui em Belo Horizonte... (Professor Francisco Bastos Gil, Entrevista, 03/07/2013).

Ao falarem sobre seus professores, nossos entrevistados se recordaram nitidamente das aulas dos que lecionavam disciplinas matemáticas, e raramente mencionaram as aulas das disciplinas pedagógicas, o que certamente reflete a presença marcante das primeiras e a pequena participação das últimas na formação propiciada pelo curso em seu período inicial.

A matriz curricular do curso estudado era composta originalmente, conforme foi comentado, por disciplinas que perfaziam 2720 horas-aula. $O$ exame da distribuição dessa carga horária evidencia imediatamente a presença muito reduzida de disciplinas de natureza didático-pedagógica, segundo as exigências legais e as concepções sobre as licenciaturas na época. Essas disciplinas, apenas quatro - Didática, Psicologia da Educação: Adolescência, Aprendizagem, Elementos de Administração Escolar e Prática de Ensino - totalizavam 390 horas-aula, o que corresponde a cerca de 14\% da carga do curso. Por outro lado, 1550 horas-aula eram reservadas para as disciplinas exclusivamente matemáticas de Geometria Analítica, Cálculo Diferencial e Integral, Álgebra e Fundamentos de Matemática Elementar, ou seja, aproximadamente $57 \%$ do total. Os restantes $29 \%$ destinavam-se a disciplinas também constituídas por componentes matemáticos: Desenho Geométrico, Geometria Descritiva, Estatística, Cálculo Numérico e Física Geral. Frisamos que a distribuição adotada no curso da Fafil não era prerrogativa dele: devia-se ao currículo mínimo fixado desde 1962 pelo Ministério da Educação.

As entrevistas com professores e estudantes do curso mostraram a presença de uma concepção predominante nos anos 1960 e 1970 - a da necessidade de uma formação muito forte em Matemática. A formação pedagógica, embora percebida pelos entrevistados como capaz de subsidiar os licenciandos em relação a metodologias adequadas ao trabalho com os conteúdos matemáticos em sala de aula, não se sobressai em relação às lembranças sobre o curso. Em contraposição, os antigos estudantes e professores narraram recordações vivas de aulas das disciplinas matemáticas, referindo-se, sobretudo, às práticas do professor Francisco Gil.

O professor Francisco Gil foi enfático ao reconhecer seus "excessos" e explicar suas razões para propor questões difíceis a alunos que já eram docentes:

Como eles eram professores, eu comecei a dar aulas num nível que eu achava que era bom... Quando começaram as provas, foi aquele arraso... Eles me questionaram: "O 
senhor está doido? O senhor está matando a gente!". Aí eu falei: "É assim mesmo! E assim foi... Eles "caíram na real" e começaram a estudar mesmo. Faziam grupinhos e estudavam... E eu, descascava, porque eles eram professores, tinham que dar conta. "Mandei brasa; suguei o sangue deles até não poder mais." Ao invés de eles ficarem morrendo de raiva de mim, pelo contrário, cada vez eles gostavam mais. Parecia masoquismo. Acontece que eles corresponderam e nós fomos levando o curso. (Professor Francisco Bastos Gil, Entrevista, 03/07/2013).

É interessante cotejar a fala do professor com a de seus alunos daquela primeira turma.

Ele cobrava demais e as provas eram dificílimas. Talvez por isso, porque ele queria saber se realmente a gente sabia o conteúdo. Ele puxava bastante. A gente até brincava que o Gil tinha um livrão da capa preta que ele escondia para tirar os exercícios. [...] Nós não sabíamos que livro era esse, um livro misterioso que era só para tirar exercícios e, realmente, depois ele confessou que tinha mesmo, ele falou: "Bobos, vocês acham que eu poderia deixar vocês resolverem exercícios fáceis e me passarem pra trás?" (Professora Rosa Terezinha Paixão Durães, Entrevista, 28/11/2012).

Gil era muito exigente. Ele tinha um livro secreto que batizamos de "o livro da capa preta" para formular as "intrincadas" questões da prova. Nós estudávamos extensivamente e fazíamos todos os exercícios dos livros adotados, porém, na hora da prova, apareciam questões inesperadas que nos traziam sérias dores de cabeça. Mas, aquela turma era formada de "tarimbados" em Matemática e se o mestre não se cuidasse, todos tiravam a nota máxima. Penso que foi a turma mais forte que passou por ali. Eram mais ou menos quatro horas para realizarmos a prova. [...] A turma era muito viva e demonstrava habilidade nas disciplinas ministradas pelo Professor Gil. (Professor Juvenal Caldeira Durães, Entrevista, 29/10/2012).

O professor Gil sabia muito bem, era um mestre... As provas eram rigorosas. Ele cobrava mesmo! Com muita rigidez! Não só ele, mas, os outros também. Ele não se importava de dar zero. O aluno tinha que demonstrar conhecimento. Se não sabia era zero mesmo! (Professor Edson Guimarães, Entrevista, 28/05/2013).

Do conteúdo de geometria ele exigia uma dissertação e, por exemplo, quando caía um ponto sobre triângulos, você tinha que falar tudo sobre triângulos... [...] Havia, também, os exercícios inéditos que só na hora da aula eles eram apresentados para a gente. Dentro do conteúdo aprendido, você tinha que desenvolver aquele exercício até provar aquela verdade que foi proposta. Era um método muito interessante, fazia a gente pensar muito, tinha gente que chegava a suar. (Professora Mariza Guimarães, Entrevista, 28/05/2013).

Nossos colaboradores, ex-alunos do professor Gil, destacaram que a postura firme, comprometida e exemplar de seu mestre serviu de inspiração para que suas práticas fossem mantidas e/ou aprimoradas, haja vista que já atuavam na docência, e também, ratificaram a visão que tinham de como deveriam ser as aulas de Matemática: com exposição consistente da matéria, muitos exercícios e uma boa dose de rigor.

Os relatos dos ex-alunos acerca de sua formação matemática evidenciam uma concepção absolutista desses conhecimentos, portadores das verdades absolutas, indiscutíveis, representantes do saber genuíno. Acreditamos que, na formação desses estudantes que já eram professores e que vieram a se tornar os docentes do mesmo curso em que se graduaram, tiveram grande repercussão as compreensões de seus formadores 
sobre a natureza da Matemática, que ecoaram em suas falas como modelos a serem seguidos, como opções para o tratamento do conhecimento matemático. Moreira e Ferreira (2013) esclarecem que é possível situar em duas vertentes principais o modo de conceber o conhecimento matemático da formação do professor de Matemática. Em uma delas, privilegia-se a formação essencialmente conteudista, enquanto na outra a atenção se volta para a mescla de conhecimentos relacionados ao ensino e à aprendizagem em geral e da Matemática em particular, à educação como processo social e à escola. Nossa pesquisa constatou a preponderância completa da primeira vertente nos momentos iniciais do curso estudado.

É preciso ressaltar, no entanto, que nos depoimentos coletados por nós foram muito acentuadas as dificuldades enfrentadas e vencidas e mostrou-se fortemente a concepção de que o curso de Matemática era difícil, destinado a poucos.

Na minha turma de 1972 começaram trinta e terminaram cinco. Na verdade, Matemática não é um curso para pessoas que não gostam de pensar, de raciocinar e que não buscam o conhecimento por si só... É um curso pesado. Você tinha que dar conta de álgebra, das derivadas... (Professora Ruth Tolentino, Entrevista, 03/12/2012).

Na minha turma, nós éramos cinquenta, porque era o número de acadêmicos que entrava pelo vestibular. Mas concluíram o curso somente oito. A evasão acontecia porque o curso era muito puxado. No primeiro ano, a turma se reduzia à metade e a cada ano ia diminuindo... O curso de Matemática era muito pesado. (Professora Dilma Silveira Mourão, Entrevista, 03/12/2012).

Documentos escritos (MONTES CLAROS, 1990) mostram que, de fato, o número de concluintes do curso era pequeno. Até 1978, formaram-se 80 alunos, assim distribuídos por ano: 1971 (16), 1972 (4), 1973 (7), 1974 (12), 1975 (12), 1976 (8), 1977 (14) e 1978 (17).

Algumas explicações para a grande evasão e reprovação podem ser elencadas. Uma delas, que nos pareceu a mais relevante, seria a necessidade de tempo e dedicação aos estudos, considerando que a maioria dos estudantes eram trabalhadores durante o dia e frequentavam o curso à noite. Outra ideia plausível está no ingresso, no curso de Matemática, de alunos sem qualquer afinidade com a licenciatura, apenas em razão da oportunidade de obtenção de um diploma de curso superior na mesma cidade em que residiam. A realidade dos estudos, configurada pelos conteúdos trabalhados, metodologia usada nas aulas e procedimentos e critérios de avaliação não correspondiam às expectativas desses estudantes, que abandonaram o curso. Esses dois fatores, 0 econômico e o pessoal, de grau de satisfação dos estudantes com o curso em que ingressaram, estão entre os arrolados na ampla revisão bibliográfica sobre o fenômeno da evasão empreendida por Lima e Machado (2014). Entretanto, outras perspectivas apontadas no estudo dessas autoras, imbricadas ou não às duas possíveis explicações enfatizadas acima, nos parecem ter repercutido no abandono do curso investigado. Entre elas, realçamos a integração insuficiente dos alunos com o ambiente acadêmico e social da instituição; seu contexto familiar, social e institucional; a desinformação e a frustração das expectativas quanto ao curso e à carreira profissional por eles visada, incluído nesse aspecto o baixo prestígio social da docência; o rendimento acadêmico obtido nos primeiros períodos - geralmente aqueles em que se verificam os maiores índices de reprovação. Acreditamos, portanto, que a conjugação de todos esses fatores condicionou a não 
conclusão do curso pela maior parte de seus ingressantes.

\section{Considerações finais}

Nossa pesquisa mostrou que a criação da Fafil e a implementação do curso de Matemática possibilitaram a formação acadêmica e profissional de sujeitos de muitas localidades norte mineiras, que tiveram a opção de permanecer em sua comunidade de origem e contribuir para o desenvolvimento de sua região. Como salientamos, a implantação do curso de Matemática se deu num cenário de carências de docentes tanto para o ensino secundário como para o superior. Mesmo tendo, conforme foi comentado, formado poucos licenciados em sua fase inicial, o curso teve egressos suficientes para suprir algumas demandas e se manter em funcionamento desde sua criação. Ele passou por várias mudanças, como a transformação em curso de Ciências, as quais não são contempladas no presente texto, e que serão tema de outros artigos.

Parece-nos importante assinalar, aqui, um aspecto importante destacado nas reflexões e considerações de nossos depoentes, estudantes das primeiras turmas e futuros docentes do curso, visto que esse aspecto indubitavelmente repercutiu no desenvolvimento da formação de professores de Matemática na região, ainda que não seja exclusivo da licenciatura que estudamos. Trata-se da concepção de que a Matemática é um conjunto de conhecimentos muito difíceis, reservado a um número pequeno de pessoas. Essa ideia, veiculada frequentemente nas falas de nossos entrevistados, nos remete ao conceito de distinção tratado por Bourdieu (2007), no qual as práticas culturais incentivadas pela família e pela escola distinguem o que será reconhecido como gosto legítimo, ou seja, o gosto e as preferências são submetidos a uma lógica interna de um determinado grupo que deseja evidenciar seu pertencimento e seu status privilegiado em relação a outro. As escolhas são modos de estabelecer distinções sociais, estratégias de marcar o lugar social e o grupo a que pertence cada indivíduo. Desse modo, alguns daqueles que concluíram o curso de Matemática da Fafil proferem o discurso de sua qualidade precisamente devido a sua dificuldade e sua característica de formar poucas pessoas. Sobressaíam-se somente os mais inteligentes ou mais dedicados - justamente os concluintes do curso - nossos depoentes. Nas narrativas de nossos colaboradores, a evasão e a reprovação representam, assim, marcas de distinção do curso (BOURDIEU, 2007), e, consequentemente, de sua qualidade.

Outro ponto relevante é o que diz respeito ao tipo de formação propiciado pelo curso, cuja intenção principal era atender à necessidade de professores para a região. É muito evidente que a formação matemática desempenhava papel preponderante, com as disciplinas pedagógicas ocupando lugar muito pequeno. Essa característica é comum às licenciaturas em Matemática da época e ainda pode ser observada nos cursos atuais.

As concepções quanto ao que significa ser um bom professor de Matemática dos licenciados pelo curso investigado foram moldadas, em grande parte, pelo docente responsável pela maioria das disciplinas matemáticas nos primórdios desse curso, Francisco Bastos Gil. Nas falas de seus antigos alunos, entrevistados por nós, a boa exposição, o quadro organizado, o rigor, a exigência nas provas foram extremamente valorizados. As considerações desse docente tão marcante no curso de Montes Claros esvaziam o saber pedagógico como componente da formação do professor, acentuando sobremaneira a concepção de que saber transmitir o conhecimento é algo essencial ao 
professor, mas esse saber não é específico e pode ser ensinado aos futuros professores: trata-se de uma capacidade inata. Francisco Gil, ao referir-se a um de seus antigos professores, disse: Para ser um bom professor de Matemática, é necessário ter dom [...] Era competentíssimo. Mas não sabia, nunca soube, nunca teve didática, nunca soube explicar uma coisa óbvia [...] A maneira de você falar, de explicar conta muito... Agora isso você não aprende. Isso é dom de convencer as pessoas. (Professor Francisco Bastos Gil, Entrevista, 03/07/2013).

Finalizando, podemos dizer que o processo de formação de professores que investigamos não se diferencia de outros processos de implantação de cursos de Matemática brasileiros nas décadas de 1960 e 1970. Configurados sob o signo da carência e da urgência (GARNICA, 2010), esses cursos vivenciaram a falta de estrutura física, materiais e recursos humanos e se estabeleceram à luz da legislação da época quanto a diversos aspectos, entre os quais os curriculares, centrados nas disciplinas matemáticas. Podemos dizer, ainda, que a instituição montes-clarense, em seus primeiros tempos, manteve um modelo de formação calcado no rigor e na distinção (BOURDIEU, 2007), predominando a ideia de que as tarefas de ensinar e aprender Matemática eram destinadas aos bem-dotados intelectualmente.

O discurso relativo à existência de capacidades inatas específicas para a Matemática, sem dúvida, é resultado de construções históricas que parecem arraigadas entre estudantes e professores. Constatado em nossa pesquisa nas décadas de 1960 e 1970, tem permanecido e sido estudado em contextos posteriores ao focalizado neste trabalho.

Ainda que não nos seja possível estender-nos sobre o tema, é oportuno lembrar resultados da investigação empreendida por Cruz e Maia (2011) a partir da Teoria das Representações Sociais, que focalizou representações sociais do professor de matemática. A pesquisa dessas autoras envolveu mais de 500 sujeitos, entre alunos do Ensino Básico e Superior e professores de matemática de instituições públicas e privadas do estado de Pernambuco, e revelou "uma dimensão cognitiva positiva relacionada à superioridade cognitiva do professor de matemática" como uma representação dos estudantes, "entendida como uma condição inata" (CRUZ; MAIA, 2011, p. 240). Conforme compreendem as pesquisadoras, o domínio do conhecimento matemático confere aos professores dessa disciplina uma imagem de genialidade que não apenas tipifica a concepção inatista da superioridade de alguns indivíduos em relação a outros, mas também se configura como fator de peso na exclusão a partir da escola. A mesma pesquisa aponta que os estudantes, simultaneamente, representam os professores de matemática como antissociais, prepotentes, amedrontadores, distantes, "por serem mais inteligentes do que os demais". (ibidem, p. 243).

Percebemos que concepções quanto à presença de um dom específico contribuem para a perpetuação do mito da inteligência superior dos bem-sucedidos nos estudos matemáticos, que acarreta prejuízos inegáveis para a educação em geral e a formação de professores em particular. Em nosso trabalho, evidenciou-se fortemente a presença dessas concepções, que certamente repercutiram no desempenho dos licenciandos do curso de Matemática da Faculdade de Filosofia, Ciências e Letras de Montes Claros no período 1968-1978. 


\section{Referências}

AMADO, J.; FERREIRA, M. de M. (Coord.). Usos \& abusos da história oral. 8 ed. Rio de Janeiro: Editora FGV, 2006.

BARALDI, I. M. Retraços da educação matemática na região de Bauru (SP): uma história em construção. 2003. 3 v. 288 f. Tese (Doutorado em Educação Matemática) - Instituto de Geociências e Ciências Exatas, Universidade Estadual Paulista, Rio Claro/SP, 2003.

BARALDI, I. M.; GAERTNER, R. Textos e contextos: um esboço da CADES na história da educação (Matemática). Blumenau: Edifurb, 2013.

BOURDIEU, Pierre. A distinção. Crítica social do julgamento. Porto Alegre: Zouk, 2007.

A ilusão biográfica. In: AMADO, J.; FERREIRA, M. de M. (Coord.). Usos \&

$\overline{\text { abusos }}$ da história oral. 8 ed. Rio de Janeiro: Editora FGV, 2006, p. 183-191.

BRASIL. DOCUMENTA. Brasília: Conselho Federal de Educação, oㅜ 10, dez. 1962.

CASTRO, A. D. de. A licenciatura no Brasil. Revista de História, São Paulo, v. 50, n. 100, tomo II, p. 627-652, out./dez. 1974.

CRUZ, F. M. L.; MAIA, L. de S. L. Genialidade e loucura nas representações sociais do professor de matemática segundo professores e estudantes. Práxis Educativa, v. 6, n. 2, p. 235-247, 2011.

CUNHA, L. A. Os estudos de problemas brasileiros na UFRJ: aproximações institucionais. Revista Contemporânea de Educação, Rio de Janeiro, v. 7, n. 13, p. 193-215, 2012.

CURY, F. G. Uma história da formação de professores de Matemática e das instituições formadoras do estado do Tocantins. Rio Claro, 2011. $289 \mathrm{f}$. Tese (Doutorado em Educação Matemática) - Instituto de Geociências e Ciências Exatas, Universidade Estadual Paulista, Rio Claro/SP, 2011.

DRUMOND, J. G. de F. "Universitas quae sera tamen”. Montes Claros: Revista Vínculo, n. 04, p. 11-13, 1989.

FERNANDES, D. N. Sobre a formação do professor de Matemática no Maranhão: cartas para uma cartografia possível. 2011. 389 f. Tese (Doutorado em Educação Matemática) Instituto de Geociências e Ciências Exatas, Universidade Estadual Paulista, Rio Claro/SP, 2011.

GALVÃO, A. M. de O.; LOPES, E. M. T. Território plural: a pesquisa em história da educação. 1 ed. São Paulo: Ática, 2010.

GARNICA, A. V. M. História oral em educação matemática: outros usos, outros abusos. Guarapuava: Sociedade Brasileira de História da Matemática, 2007.

Presentificando ausências: a formação e a atuação dos professores de matemática. In: CUNHA, A. M. de O.; MORTIMER, E. F.; AGUIAR JUNIOR, O. G. de; NASCIMENTO, S. S. do; FONSECA, M. C. F. R. Convergências e tensões no campo da formação e do trabalho docente: educação ambiental, educação em ciências, educação em espaços não-escolares, educação matemática. Belo Horizonte: Autêntica, 2010, p. 555-569.

Registrar oralidades, analisar narrativas: sobre pressupostos da história oral em educação matemática. Ciências Humanas e Sociais em Revista, v. 32, p. 20-35, 2010.

GARNICA, A. V. M.; FERNANDES, D. N.; SILVA, H. da. Entre a amnésia e a vontade de nada esquecer: notas sobre regimes de historicidade e história oral. Bolema - Boletim de Educação Matemática, v. 25, p. 213-250, 2011.

LIMA, E.; MACHADO, L. A evasão discente nos cursos de licenciatura da Universidade 
Federal de Minas Gerais. Educação Unisinos, v. 18, n. 2, p. 121-129, 2014.

MARTINS-SALANDIM, M. E. A interiorização dos cursos de Matemática no estado de São Paulo: um exame da década de 1960. 2012. 379 f. Tese (Doutorado em Educação

Matemática) - Instituto de Geociências e Ciências Exatas, Universidade Estadual Paulista, Rio Claro/SP, 2012.

MINAS GERAIS. Constituição (1989). Constituição do Estado de Minas Gerais, 1989. Belo Horizonte, 1989.

1994.

. Fundação João Pinheiro. Anuário Estatístico do Nordeste. FJP: Belo Horizonte,

MONTES CLAROS. Relatório de Gestão 1990 - UNIMONTES. Montes Claros: UNIMONTES, 1990.

MOREIRA, P. C.; FERREIRA, A. C. O lugar da Matemática na Licenciatura em Matemática. Bolema - Boletim de Educação Matemática, v. 27, n. 47, p. 981-1005, 2013.

PAULA, I. R. de. Pequena resenha histórica da FAFIL. Montes Claros: Revista Vínculo, Ano I, n. 01, p. 9-12, 1973.

ROTA JÚNIOR, C.; IDE, M. H. de S. Ensino superior e desenvolvimento regional: o norte de Minas Gerais na década de 1960. Revista Brasileira de Educação, v. 21, n. 64, p. 143164, 2016.

\section{Fontes orais}

BARBOSA, Ruth Tolentino. Entrevista. [2012]. Entrevistadora/transcritora: Shirley Patrícia Nogueira de Castro e Almeida. Montes Claros, 03 dez. 2012. Depósito disponível em: <http://www2.fc.unesp.br/ghoem>.

DURÃES, Juvenal Caldeira. Entrevista. [2012]. Entrevistadora/transcritora: Shirley Patrícia Nogueira de Castro e Almeida. Montes Claros, 29 out. 2012. Depósito disponível em: $<$ http://www2.fc.unesp.br/ghoem>.

DURÃES, Rosa Terezinha Paixão. Entrevista. [2012]. Entrevistadora/transcritora: Shirley Patrícia Nogueira de Castro e Almeida. Montes Claros, 28 nov. 2012. Depósito disponível em: <http://www2.fc.unesp.br/ghoem>.

FERREIRA, Ronaldo Dias. Entrevista. [2013]. Entrevistadora/transcritora: Shirley Patrícia Nogueira de Castro e Almeida. Montes Claros, 20 mai. 2013. Depósito disponível em: $<$ http://www2.fc.unesp.br/ghoem>.

GIL, Francisco Bastos. Entrevista. [2013]. Entrevistadora/transcritora: Shirley Patrícia Nogueira de Castro e Almeida. Montes Claros, 03 jul. 2013. Depósito disponível em: <http://www2.fc.unesp.br/ghoem>.

GUIMARÃES, Edson. Entrevista. [2013]. Entrevistadora/transcritora: Shirley Patrícia Nogueira de Castro e Almeida. Montes Claros, 28 mai. 2013. Depósito disponível em: <http://www2.fc.unesp.br/ghoem>.

GUIMARÃES, Mariza Monteiro. Entrevista. [2013]. Entrevistadora/transcritora: Shirley Patrícia Nogueira de Castro e Almeida. Montes Claros, 28 mai. 2013. Depósito disponível em: <http://www2.fc.unesp.br/ghoem>.

MOURÃO, Dilma Silveira. Entrevista. [2012]. Entrevistadora/transcritora: Shirley Patrícia Nogueira de Castro e Almeida. Montes Claros, 03 dez. 2012. Depósito disponível em: $<$ http://www2.fc.unesp.br/ghoem>.

PAIXÃO, Maria de Lourdes Ribeiro. Entrevista. [2013]. Entrevistadora/transcritora: Shirley 
Patrícia Nogueira de Castro e Almeida. Montes Claros, 23 mai. 2013. Depósito disponível em: <http://www2.fc.unesp.br/ghoem>.

PAULA, Isabel Rebello de. Entrevista. [2014]. Entrevistadora/transcritora: Shirley Patrícia Nogueira de Castro e Almeida. Montes Claros, 24 jan. 2014. Depósito disponível em: $<$ http://www2.fc.unesp.br/ghoem>.

RIBEIRO, Rosina Rabelo Nuzzi. Entrevista. [2013]. Entrevistadora/transcritora: Shirley Patrícia Nogueira de Castro e Almeida. Montes Claros, 04 jun. 2013. Depósito disponível em: <http://www2.fc.unesp.br/ghoem>.

SANTOS, Edson Crisóstomo dos. Entrevista. [2013]. Entrevistadora/transcritora: Shirley Patrícia Nogueira de Castro e Almeida. Montes Claros, 13 jun. 2013. Depósito disponível em: <http://www2.fc.unesp.br/ghoem>.

SOBREIRA, Maria Isabel Magalhães de Figueiredo. Entrevista. [2013].

Entrevistadora/transcritora: Shirley Patrícia Nogueira de Castro e Almeida. Montes Claros, 02 jul. 2013. Depósito disponível em: <http://www2.fc.unesp.br/ghoem>.

SOUZA, João Barbosa de. Entrevista. [2013]. Entrevistadora/transcritora: Shirley Patrícia Nogueira de Castro e Almeida. Montes Claros, 28 mai. 2013. Depósito disponível em: $<$ http://www2.fc.unesp.br/ghoem>.

SOUZA, Sebastião Alves de. Entrevista. [2013]. Entrevistadora/transcritora: Shirley Patrícia Nogueira de Castro e Almeida. Montes Claros, 21 mai. 2013. Depósito disponível em: <http://www2.fc.unesp.br/ghoem>.

WANDERLEY, Wandaick. Entrevista. [2013]. Entrevistadora/transcritora: Shirley Patrícia Nogueira de Castro e Almeida. Montes Claros, 25 jun. 2013. Depósito disponível em: $<$ http://www2.fc.unesp.br/ghoem>.

SHIRLEY PATRÍCIA NOGUEIRA DE CASTRO E ALMEIDA é professora do Departamento de Métodos e Técnicas Educacionais na Universidade Estadual de Montes Claros (Montes Claros/MG, Brasil) e Doutora em Educação pela Universidade Federal de Minas Gerais (Belo Horizonte/MG, Brasil).

Endereço: Avenida Ruy Braga, s/no, Campus Universitário Professor Darcy Ribeiro, Prédio 2, Vila Mauricéia - 39.401-089 - Montes Claros/MG - Brasil.

E-mail: shirley.castroalmeida@yahoo.com.br

MARIA LAURA MAGALHÃES GOMES é professora do Departamento de Matemática e Programa de Pós-Graduação em Educação na Universidade Federal de Minas Gerais (Belo Horizonte/MG, Brasil); Doutora em Educação pela Universidade Estadual de Campinas (Campinas/SP, Brasil) e Bolsista de Produtividade do CNPq.

Endereço: Avenida Antônio Carlos, 6627 - 31270-901 - Pampulha/SP - Brasil.

E-mail: mlauramgomes@gmail.com

Recebido em 01 de julho de 2016.

Aceito em 25 de novembro de 2016. 